\title{
Pro-inflammatory cytokines for evaluation of inflammatory status in endometriosis
}

\author{
ANDREI M. MALUTAN, TUDOR DRUGAN, NICOLAE COSTIN, RAZVAN CIORTEA, \\ CARMEN BUCURI, MARIA P. RADA, DAN MIHU
}

"Iuliu Hatieganu” University of Medicine and Pharmacy, Cluj-Napoca, Romania

\begin{abstract}
The aim of the study was to investigate the serum pro-inflammatory cytokine profile in patients with diagnosed endometriosis.

Material and methods: The study included 160 women, who were divided in two study groups (Group I-endometriosis; Group 2 - healthy). We evaluated the serum levels of interleukin (IL)-1 $\beta$, $I L-5, I L-6, I L-7$, and IL-12, and of tumour necrosis factor $\alpha(T N F-\alpha)$ with the use of Human Multiplex Cytokine Panels.

Results: The serum level of IL-1 $\beta, I L-6$, and TNF- $\alpha$ is significantly higher in women with endometriosis compared to women free of disease, from the control group (mean 10.777, 183.027, and 131.326, respectively, compared to 3.039, 70.043, and 75.285, respectively; $p=0.002, p<0.001$, and $p=0.015$, respectively). No significant differences in the serum levels of $I L-5$ and $I L-12$ were observed between the studied groups, and IL-7 had a very low detection rate.

Conclusions: Women with endometriosis have elevated levels of key pro-inflammatory cytokines, i.e. $I L-1 \beta, I L-6$, and TNF- $\alpha$. At the same time, IL-1 $\beta$ and IL-6 could be used as predictors for endometriosis.
\end{abstract}

Key words: inflammation, endometriosis, cytokine, interleukin.

(Centr Eur J Immunol 2015; 40 (1): 96-102)

\section{Introduction}

Endometriosis is a pelvic inflammatory condition defined as the presence of ectopic deposits of endometrial tissue outside of the uterine cavity. The disease manifests clinically through various forms of pelvic pain or subfertility. The presence of pelvic endometriosis is about 5-10\% in the general population, but in women with pelvic pain, infertility, or both, the prevalence is $35-50 \%$ [1], with some authors reporting as high as $82 \%$ prevalence in these patients [2]. This variability could be due to the difficulty in non-surgical diagnosis. The gold standard in diagnosing endometriosis is diagnostic laparoscopy. On the other hand, it is an invasive procedure with potential hazards, which can include major vessel or bowel injury [3]. A simple blood test for prediction and diagnosis of endometriosis would overcome these problems and have a major impact on women's health.

Immune system alterations are thought to be involved in the development of endometriosis, especially a dysfunction in immune-related cells and macrophages within the peritoneum secreting a number of products, mainly cytokines and growth factors $[4,5]$. At this level, there is an immune-inflammatory reaction that activates immune cells, together with endometriotic implants, producing high amounts of cytokines, growth factors, and angiogenic products [6]. However, systemic immune alterations have also been described in endometriosis, with activation of peripheral blood monocytes, which secrete high levels of cytokines [7]. Several cytokines, including interleukin 6 (IL-6), vascular endothelial growth factor (VEGF), and tumour necrosis factor $\alpha$ (TNF- $\alpha$ ), have been studied in the pathogenesis of endometriosis. Interleukin 6 is considered to play a potential role in the growth and/or maintenance of ectopic endometrial tissue. Interleukin 6 is a regulator of inflammation and immunity that modulates secretion of other cytokines, promotes T-cell activation and B-cell differentiation, and inhibits growth of various cell lines. The role of IL-6 in the pathogenesis of endometriosis has been extensively studied, but the levels of IL- 6 detected both in the peritoneal fluid and in the serum of patients with endometriosis have been inconsistent $[8,9]$. Tumor necrosis factor $\alpha$ is secreted from activated macrophages, and it has potent inflammatory, cytotoxic, and angiogenic effects. It is known to stimulate the expression of matrix metalloproteinases by endometriotic tissues, and matrix metalloproteinases actively participate in the invasion and matrix remodelling of endometriotic lesions [10]. Moreover, etanercept, an anti-TNF therapy, was found to effec-

Correspondence: Tudor Drugan, "Iuliu Hatieganu" University of Medicine and Pharmacy, Victor babes nr. 6 ,

400160 Cluj-Napoca, Romania, e-mail: malutan.andrei@gmail.com 
tively reduce the development of endometriosis [11]. Some authors observed that increased production of these factors in the peritoneal fluid was associated with the elevation of similar factors in the peripheral blood of patients with endometriosis [12].

The present study aimed to investigate the serum pro-inflammatory cytokine profile in patients with endometriosis compared with healthy controls, and to evaluate the sensitivity and specificity of any single cytokine or a combination of cytokines in the prediction of the inflammatory status in endometriosis.

\section{Material and methods}

\section{Study population and design}

A case-control study was conducted between June 2013 and June 2014 in "Dominic Stanca" Obstetrics and Gynaecology Clinic, Cluj-Napoca, Romania.

The study included 160 patients admitted to the clinic, who were divided into two groups as follows: Group I (endometriosis group) - 80 women with regular menses, and with no history of pelvic infections, autoimmune and neoplastic diseases, undergoing laparoscopy or laparotomy for suspected endometriosis. The evidence of endometriosis was verified by histopathological analysis. The severity of endometriosis was staged according to the revised American Society for Reproductive Medicine (rASRM) classification [13]. Group II (control group) - 80 healthy non-pregnant women aged between 18 and 40 years old, without clinical and paraclinical evidence of endometriosis.

Exclusion criteria were as follows: previous pelvic surgeries, history of cancer, suspected malignancy, adenomyosis or leiomyoma, pre-surgical suspicion of evidence of premature ovarian failure, or the use of ovarian suppressive drugs, such as oral contraceptives, GnRH agonists, progestins, or danazol in the preceding six months. None of the patients had taken anti-inflammatory medications or had been diagnosed with an inflammatory or infectious condition for $\geq 6$ months before the study.

The study protocol was approved by the Local Ethics Committee of "Iuliu Hațieganu" University of Medicine and Pharmacy, Cluj-Napoca, Romania, and signed informed consent was received from each woman before sample collection. The study was conducted under the tenets of the Helsinki Declaration.

Data was collected for each subject included in the study in a form containing general and anthropometric data (weight, height), the heredo-collateral history, personal pathological history, and data on the age and onset of symptoms. The body mass index (BMI) was calculated as the ratio between the weight $(\mathrm{kg})$ and the squared height (in metres). A total of $5 \mathrm{ml}$ of venous blood was collected from each patient before breakfast, which was centrifuged, and the serum obtained was stored at $-70^{\circ} \mathrm{C}$ for future determinations.

\section{Cytokine evaluation}

We used multiplex cytokine kits (Invitrogen Human Cytokine 30-Plex Panel, LHC6003) in order to measure serum levels of IL-1 $\beta$, IL-5, IL-6, IL-7, IL-12, and TNF- $\alpha$. Dose measurements were performed with the use of a Luminex 200 system (Luminex Corporation, Austin, TX, USA) in accordance with the manufacturer's specifications (Invitrogen Corporation, Carlsbad, CA, USA). The sensitivity of the test was specified by the manufacturer (Invitrogen Corporation, Carlsbad, CA, USA) in the informative material included in the kits.

The average sensitivity of the test for IL- $1 \beta$ was $5 \mathrm{pg} /$ $\mathrm{ml}$, with an inter-assay variation coefficient of $4.8 \%$. For IL-5, the average sensitivity of the test was $0.5 \mathrm{pg} / \mathrm{ml}$ with an inter-assay variation coefficient of $7.5 \%$. The average sensitivity of the test for IL-6 was $0.5 \mathrm{pg} / \mathrm{ml}$ with an inter-assay variation coefficient of $7 \%$. In the case of IL-7, the average sensitivity of the test was $10 \mathrm{pg} / \mathrm{ml}$ with an inter-assay variation coefficient of $9.8 \%$. The sensitivity of the test for IL-12 was $1 \mathrm{pg} / \mathrm{ml}$, and the inter-assay variation coefficient of $8.1 \%$. The test for TNF- $\alpha$ revealed an average sensitivity of $0.5 \mathrm{pg} / \mathrm{ml}$, with inter-assay variation coefficient of $8.3 \%$.

\section{Statistical analysis}

Statistical analyses were performed using Microsoft Excel and IBM SPSS software (version 22.0). Data is presented as median and quartiles for the groups because the standard deviation was of importance. We performed an analysis for the significances of the observed differences with the median test for independent samples; also Pearson's $\chi^{2}$ test with and without the continuity correction, and Fisher exact test were used as statistical tests. $P$ values less than 0.05 were regarded as significant. Because the study we had conducted was a case-control study, the predictive values (PPV - positive predictive value and NPV - negative predictive value) were calculated with the Bayesian approximation, assuming an endometriosis prevalence of $10 \%$.

\section{Results}

Tables 1 and 2 present the biometry data and inflammatory markers considered for the study. Almost all of the cases from the endometriosis group were staged as III $(30-37.50 \%)$ or IV $(47-58.75 \%)$, and only 3 cases $(3.75 \%)$ were in stage II of endometriosis, according to rASRM staging criteria.

Table 3 presents the data obtained by inferential statistic (the independent samples median-test probability), which show that mean serum levels of IL-1 $\beta$, IL-6, and 
Table 1. Descriptive statistics of the endometriosis and control groups

\begin{tabular}{lcccc}
\hline Variable & Calculated parameters & Endometriosis group & Control group & Average \\
\hline age $(\mathrm{yr})$ & mean $\pm \mathrm{SD}$ & $30.600 \pm 5.486$ & $26.350 \pm 2.131$ & $28.475 \pm 4.655$ \\
\hline weight $(\mathrm{kg})$ & mean $\pm \mathrm{SD}$ & $62.050 \pm 9.067$ & $56.925 \pm 8.094$ & $59.488 \pm 8.920$ \\
\hline height $(\mathrm{cm})$ & mean $\pm \mathrm{SD}$ & $164.725 \pm 5.114$ & $167.225 \pm 6.773$ & $165.975 \pm 6.094$ \\
\hline BMI $\left(\mathrm{kg} / \mathrm{cm}^{2}\right)$ & mean $\pm \mathrm{SD}$ & $22.912 \pm 3.520$ & $20.307 \pm 2.126$ & $21.609 \pm 3.173$ \\
\hline
\end{tabular}

Table 2. Descriptive statistic of the studied pro-inflammatory parameters

\begin{tabular}{lcccccc}
\hline Parameter & & IL-1 $\beta$ & IL-5 & IL-6 & IL-12 & TNF- $\alpha$ \\
\hline$N$ & valid & 110 & 38 & 146 & 136 & 146 \\
\cline { 2 - 7 } & missing & 50 & 122 & 4 & 24 & 14 \\
\hline median & & 4.170 & 0.035 & 69.052 & 2.080 & 88.552 \\
\hline minimum & 0.0 & 0.0 & 11.3 & 0.2 & 0.5 \\
\hline maximum & 53.2 & 0.5 & 542.3 & 16.1 & 584.5 \\
\hline percentiles & 25 & 0.363 & 0.035 & 61.854 & 1.325 & 26.704 \\
& 50 & 4.170 & 0.035 & 69.052 & 2.080 & 88.552 \\
\cline { 2 - 7 } & 75 & 10.325 & 0.071 & 144.192 & 4.180 & 143.325 \\
\hline
\end{tabular}

Table 3. Inferential statistic for the studied markers

\begin{tabular}{lc}
\hline & $\begin{array}{c}\text { Independent samples median-test } \\
\text { probability* }\end{array}$ \\
\hline IL-1 $\beta$ & 0.010 \\
\hline IL-5 & 1 (using Fisher exact test) \\
\hline IL-6 & $<0.001$ \\
\hline IL-12 & 0.467 \\
\hline TNF- $\alpha$ & 0.026 \\
\hline${ }^{p} p<0.05$ significant difference compared to control group
\end{tabular}

TNF- $\alpha$ were significantly higher in patients with endometriosis compared to healthy controls (mean 10.777, 183.027, and 131.326, respectively, compared to 3.039, 70.043 , and 75.285, respectively; $p=0.002, p<0.001$, and $p=0.015$, respectively).

Figures 1-5 show the distribution and median of the studied markers' serum levels between the groups with a significantly higher serum level of IL-1 $\beta$, IL-6 and TNF- $\alpha$ in the endometriosis group, and no significant differences in the serum levels of IL-5 and IL-12 between the studied groups. Interleukin 7 had a very low detection rate.

Because the independent samples median test showed significant differences between the median serum levels of IL-1 $\beta$, IL-6, and TNF- $\alpha$ in endometriosis and control groups, we have also evaluated the use of these markers as a predictive factor for endometriosis. Threshold values chosen for the three parameters (IL- $1 \beta-7 \mathrm{pg} / \mathrm{ml}$, IL-6 $-125 \mathrm{pg} / \mathrm{ml}$, and TNF- $\alpha-100 \mathrm{pg} / \mathrm{ml}$ ) have minimised overlapping confidence intervals from the observed distri-

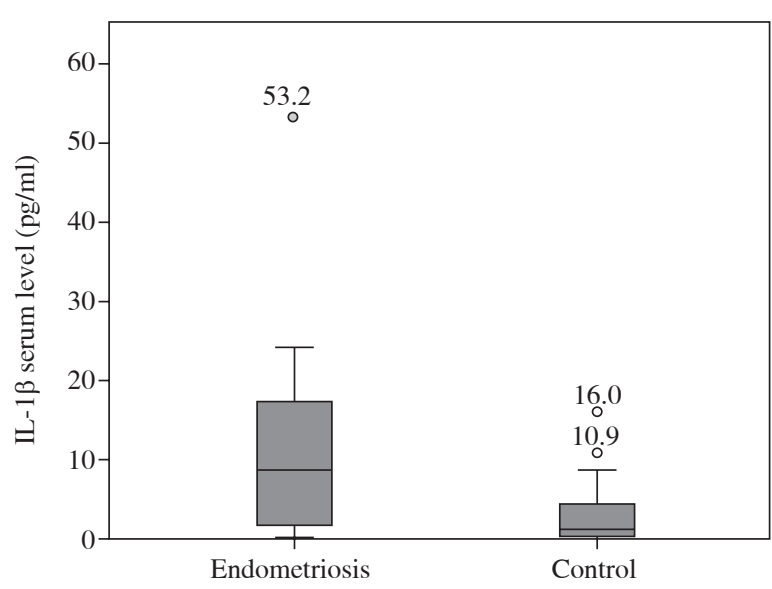

Fig. 1. Distribution of interleukin $1 \beta$ serum levels among groups

bution. We have divided the studied groups according to the three new tests as positives and negatives.

Tables 4 and 5 show the results obtained for IL- $1 \beta$ and IL-6 as a predictor of endometriosis, with statistically significant results. Pearson's $\chi^{2}$ test validated the observed differences, with a probability of 0.005 for IL- $1 \beta$ and $<0.001$ for IL-6 (with the continuity correction probability was $<0.001$ ). Table 6 shows the results obtained for TNF- $\alpha$ as a predictive test for endometriosis, showing a lack of statistical significance. Pearson's $\chi^{2}$ test failed to validate the observed differences, with a probability of 0.074 (the probability with the continuity correction was also 0.072). 


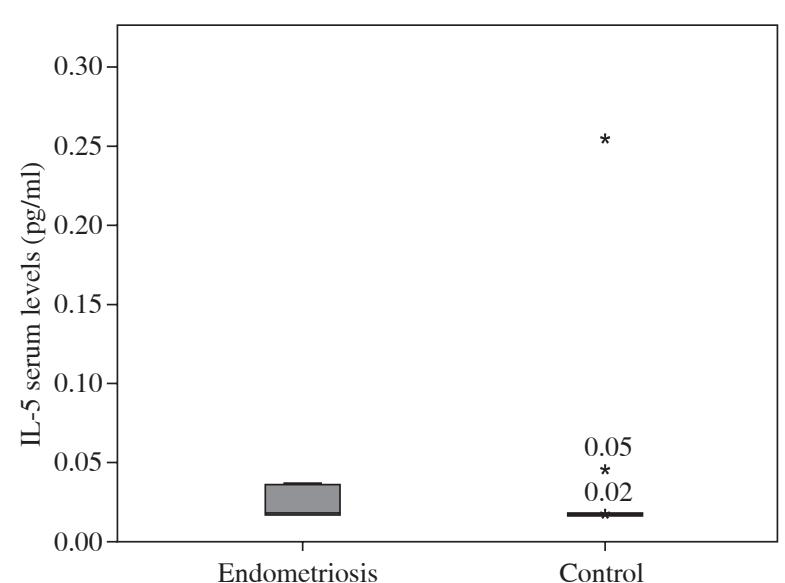

Fig. 2. Distribution of interleukin 5 serum levels among groups

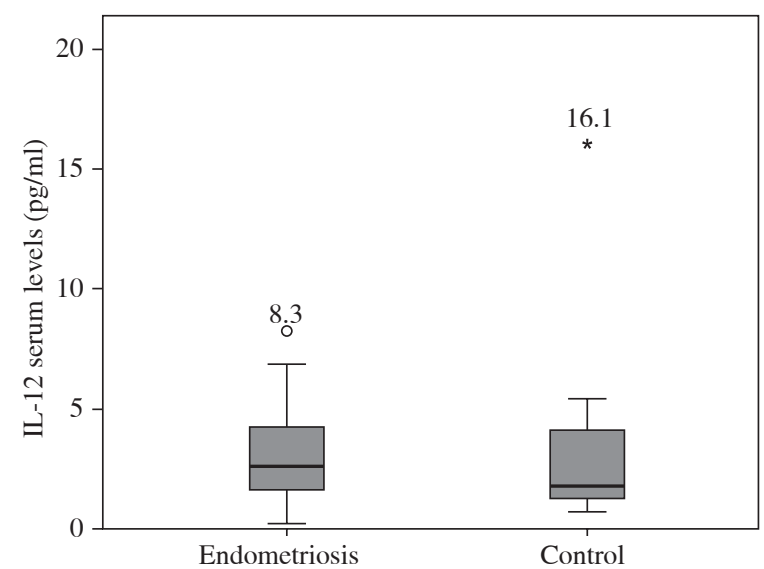

Fig. 4. Distribution of interleukin 12 serum levels among groups

Table 4. Contingency table for interleukin $1 \beta$ as the golden standard

\begin{tabular}{lccc}
\hline & $\begin{array}{c}\text { Endometriosis } \\
\text { group }\end{array}$ & $\begin{array}{c}\text { Control } \\
\text { group }\end{array}$ & Total \\
\hline Interleukin $\beta$ positive & 32 & 8 & 40 \\
\hline Interleukin 1 $\beta$ negative & 24 & 46 & 70 \\
\hline Total & 56 & 54 & 110 \\
\hline Sensitivity & & 0.571 & \\
\hline Specificity & 0.851 & \\
\hline $\begin{array}{l}\text { Positive predictive } \\
\text { value* }\end{array}$ & 0.300 \\
\hline $\begin{array}{l}\text { Negative predictive } \\
\text { value* }\end{array}$ & 0.947 \\
$\begin{array}{l}\text { *Calculated with the Bayesian approximation for case-control studies, } \\
\text { assuming a endometriosis prevalence of 10\% }\end{array}$
\end{tabular}

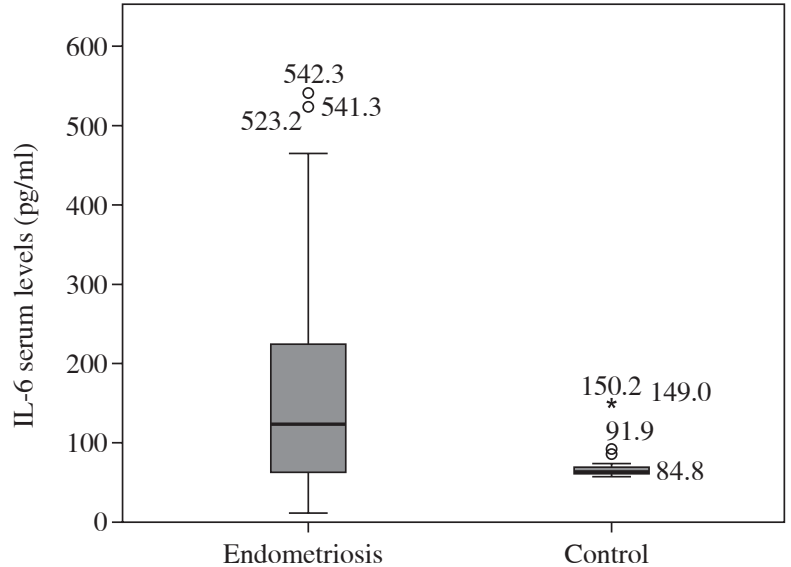

Fig. 3. Distribution of interleukin 6 serum levels among groups

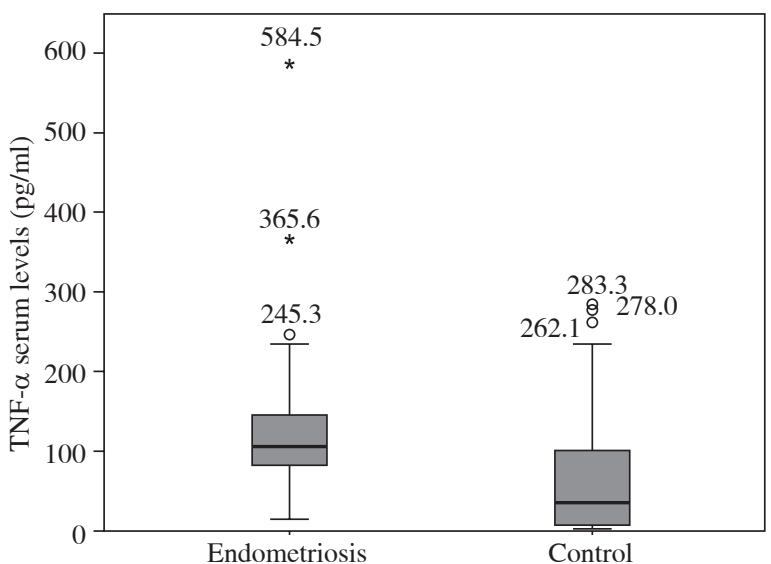

Fig. 5. Distribution of tumor necrosis factor $\alpha$ serum levels among groups

Table 5. Contingency table for interleukin 6 as the golden standard

\begin{tabular}{lccc}
\hline & $\begin{array}{c}\text { Endometriosis } \\
\text { group }\end{array}$ & $\begin{array}{c}\text { Control } \\
\text { group }\end{array}$ & Total \\
\hline Interleukin 6 positive & 38 & 4 & 42 \\
\hline Interleukin 6 negative & 38 & 76 & 114 \\
\hline Total & 76 & 80 & 156 \\
\hline Sensitivity & 0.500 & \\
\hline Specificity & 0.950 & \\
\hline $\begin{array}{l}\text { Positive predictive } \\
\text { value* }\end{array}$ & 0.526 \\
\hline $\begin{array}{l}\text { Negative predictive } \\
\text { value* }\end{array}$ & 0.945 \\
$\begin{array}{l}\text { *Calculated with the Bayesian approximation for case-control studies, } \\
\text { assuming a endometriosis prevalence of 10\% }\end{array}$
\end{tabular}


Table 6. Contingency table for tumor necrosis factor (TNF- $\alpha$ ) as the golden standard

\begin{tabular}{lccc}
\hline & $\begin{array}{c}\text { Endometriosis } \\
\text { group }\end{array}$ & $\begin{array}{c}\text { Control } \\
\text { group }\end{array}$ & Total \\
\hline TNF- $\alpha$ positive & 38 & 20 & 58 \\
\hline TNF- $\alpha$ negative & 34 & 54 & 88 \\
\hline Total & 72 & 74 & 146 \\
\hline Sensitivity & 0.527 & \\
\hline Specificity & 0.729 & \\
\hline $\begin{array}{l}\text { Positive predictive } \\
\text { value* }\end{array}$ & 0.178 \\
\hline $\begin{array}{l}\text { Negative predictive } \\
\text { value* }\end{array}$ & & & \\
\hline $\begin{array}{l}\text { *Calculated with the Bayesian approximation for case-control studies, } \\
\text { assuming a endometriosis prevalence of 10\% }\end{array}$ &
\end{tabular}

Table 7. Endometriosis stages III and IV comparison

\begin{tabular}{lc}
\hline & $\begin{array}{c}\text { Independent samples median-test } \\
\text { probability* }\end{array}$ \\
\hline Interleukin 1 $\beta$ & 1 (using Fisher exact test) \\
\hline Interleukin 5 & 1 (using Fisher exact test) \\
\hline Interleukin 6 & 0.892 \\
\hline Interleukin 12 & 0.839 \\
\hline TNF- $\alpha$ & 0.591 \\
\hline${ }^{*} p<0.05$ significant difference compared to control group
\end{tabular}

Regarding staging of the endometriosis group, no significant differences were observed in the means or median values of IL-1 $\beta$, IL-5, IL- 6 , IL-12, and TNF- $\alpha$ if the stage of endometriosis was used as a grouping parameter, between patients with endometriosis stage III and stage IV (Table 7).

\section{Discussion}

In the present study we found that in women with endometriosis there is a significantly higher serum level of IL-1 $\beta$, IL-6, and TNF- $\alpha$, compared to healthy controls. We also found that IL-5 and IL-12 did not differ significantly between women with endometriosis and women free of the disease. On the other hand, IL-7 had a very low detection rate in the studied groups, so we were unable to draw any conclusions regarding its implication.

At this moment, there are a large number of studies that support the pathophysiological implication of pro-inflammatory and anti-inflammatory cytokines such as IL-2, IL-4, IL-6, IL-8, IL-10, interferon $\gamma$ (IFN- $\gamma$ ), and TNF- $\alpha$ in endometriosis $[14,15]$.

Interleukin 6 is a cytokine derived from T cells, secreted by macrophages, lymphocytes, fibroblasts, and endothelial cells. Its secretion is increased by peritoneal macrophages in the case of endometriosis [16]. Generally, IL-6 inhibits the growth of endometrial cells, the effect of which seems to be lost in endometriotic tissues [17]. Cytokines, and specifically IL-6, have been investigated regarding the pathogenesis of endometriosis, and also as a predictor of the disease $[18,19]$. Elevated serum CA-125 and IL-6 are considered to be biological markers for differential diagnosis in endometriosis [20]. Previous studies found conflicting results regarding serum levels of IL-6 in endometriosis; however, most of them were in favour of a significant increase in IL-6 serum or peritoneal fluid (PF) levels in the case of endometriosis. Anterior reports $[21,22]$ showed significantly higher IL-6 levels in early stages of endometriosis as compared to the healthy group. Moreover, one study showed a correlation between IL-6 and pain, as well as a relation between cytokine expression and recurrences of endometriosis [23]. On the other hand, a recent study showed no statistically significant difference in serum IL-6 concentration between subjects with endometriosis and controls; consequently, the authors do not recommend measuring IL- 6 in the serum as a predictor of endometriosis. The same authors also suggested that IL-6 provides the best discrimination between subjects with endometriosis and healthy controls, and the diagnostic value of this marker increased with the finding that serum IL-6 levels did not change significantly during any phase of the menstrual cycle in either group [3, 24]. Other similar studies have shown a positive relationship between PF levels of IL-6 with severity of endometriosis $[25,26]$.

Tumor necrosis factor $\alpha$ is a pro-inflammatory cytokine produced mainly by activated macrophages. It promotes the production of other pro-inflammatory cytokines, such as IL-1, IL-6, and additional TNF- $\alpha$. It is involved in the normal physiology of endometrial proliferation and shedding [27]. It was shown that peritoneal fluid TNF- $\alpha$ concentrations are elevated in women with endometriosis, and some studies showed that higher concentrations correlate with the stage of disease. One study observed that serum TNF- $\alpha$ levels and urinary sFlt- 1 levels corrected for creatinine excretion were significantly increased in the endometriosis group [28]. Tumor necrosis factor $\alpha$ may play a central role in the local and systematic manifestations of endometriosis, on the basis of evidence showing that it promotes the growth of endometriotic cells. Moreover, some studies explored the association of TNF- $\alpha$ gene polymorphisms and endometriosis, and it seems that some polymorphisms are involved in the pathogenesis of endometriosis $[29,30]$. On the other hand, blocking TNF- $\alpha$ appears to inhibit the development of the disease in animal models [27].

Interleukin 1 is a cytokine that plays an important role in inflammation and immune response. The IL-1 family consists of IL- $1 \alpha$, IL- $1 \beta$, and IL- 1 receptor antagonist. Both IL- $1 \alpha$ and IL- $1 \beta$ are the most potent pro-inflammatory cytokines, and IL-1 receptor antagonist is a naturally 
occurring anti-inflammatory cytokine [31, 32]. A series of studies showed that there are increased concentrations of IL-1 $\beta$, IL-6, IL-10, and TNF- $\alpha$, as well as decreased VEGF in the folicular fluid (FF) of endometriosis patients [33, 34]. Moreover, Lambert et al. have shown both a significant increase in serum IL-1 $\beta$ and IL-1sRII levels in deep infiltrating endometriosis (DIE) compared to superficial endometriosis (SUP) and normal women, and suggested that a defect in the control of IL-1 can impact the pathophysiology of endometriosis [35]. On the other hand, Kalu et al. [36] found no significant difference in serum levels of platelet-derived growth factor (PDGF), IL6, Regulated on Activation, Normal T Cell Expressed and Secreted chemokine (RANTES), IL- $1 \beta$, TNF- $\alpha$, and sFas in patients with endometriosis, compared to controls.

Applying IL-1 $\beta$ and IL- 6 for the prediction of endometriosis, we found that they can be successfully used, having a specificity of 0.85 , respectively, and a specificity of 0.95 . Because IL- $1 \beta$ is not very sensitive $(0.57)$, it is recommended for use in conjunction with other tests. Tumor necrosis factor $\alpha$, used in the prediction of endometriosis, has limited value with a specificity of 0.72 .

Our results are in accordance with a recent study, which reported increased peritoneal concentrations of IL-6 and IL-10 in women with endometriosis. Analysis of the concentrations of these cytokines showed differential diagnostic usefulness for endometriosis. Peritoneal concentrations of IL-6 offer relatively good diagnostic accuracy [37]. At the same time, a very recent study has shown that at the cut-off value of $3.00 \mathrm{pg} / \mathrm{ml}$ peritoneal TNF- $\alpha$ can be a reliable screening marker for the prediction of endometriosis in adolescents [38]. In contrast with our observations, Bedaiwy et al. [12] failed to show the significance of peritoneal IL-6 levels in diagnosing women with endometriosis.

One of our main limitations is represented by the study population, which are only Caucasian women. Most of the studies present in the literature had mainly Asian origin subjects, this being considered a possible bias mark [39]. From this point of view, our population could be considered also a strength, but a more heterogenic study group would probably give more accurate results. Another limitation could be the fact that most of the patients included in the study were stage III or IV (96.25\%) and the lack of differentiation between patients with ovarian endometriomas (OE) and patients with DIE. As the study was conducted in a University Clinic, the patients addressing for treatment and included in the study had late stages of endometriosis, thus the low rate of early stages. Probably future studies could include patients presenting for unexplained infertility undergoing exploratory laparoscopy, and thus including patients with early stages discovered incidentally. On the other hand, OE and DIE are considered two distinct entities of endometriotic disease, and accordingly it is accepted that endometriosis progresses to cystic ovarian disease and pelvic adhesions in some women, to deeply infiltrating disease in other women, and sometimes to both stages of severe disease in the same woman [5]. A recent study has found a high positive correlation between serum levels of IL-6 and IL-8 in patients with OE, but not in the DIE and control groups [7]. One last limitation could be represented by the severity of endometriosis in the study population. Most of the recruited patients had advanced endometriosis, OE, or DIE, and consequently a differentiation in serum levels of the studied markers between patients with SUP and OE or DIE was not possible. We could also take in consideration the detection sensitivity of multiplexed immunoassays. It was shown that, while multiplexed immunoassays have sensitivity comparable to conventional ELISA, it is possible that the robustness may vary among different multiplex bead arrays [40].

In conclusion, we examined the possible differences in pro-inflammatory cytokine serum levels from patients with endometriosis compared to healthy controls using a multiplexed cytokine assay. We have shown that IL-1 $\beta$, IL-6, and TNF- $\alpha$ serum levels are significantly higher in women with endometriosis compared to women free of disease, from the control group, and that there is no difference in the serum levels of IL-5 and IL-12 between these patients. More importantly, our study showed that IL- $1 \beta$ and IL-6 could be used as a non-surgical diagnostic test for endometriosis. Further studies are necessary to clarify and confirm the role of pro-inflammatory cytokines in the pathogenesis of endometriosis, and moreover to find a suitable predictive model for early diagnosis.

\section{The authors declare no conflict of interest.}

This paper was published under the frame of the European Social Fund, Human Resources Development Operational Programme 2007-2013, project no. POSDRU/159/1.5/S/138776.

\section{References}

1. Giudice LC, Kao LC (2004): Endometriosis. Lancet 364: 1789-1799.

2. Mounsey A, Wilgus A, Slawson DC (2006): Diagnosis and management of endometriosis. Am Fam Physician 74: 594600 .

3. Othman Eel-D, Hornung D, Salem HT, et al. (2008): Serum cytokines as biomarkers for nonsurgical prediction of endometriosis. Eur J Obstet Gynecol Reprod Biol 137: 240-246.

4. Yagmur E, Bastu E, Karamustafaoglu-Balci B, et al. (2013): Non-invasive diagnosis of endometriosis based on a combined analysis of four plasma biomarkers. Centr Eur J Immunol 38: 154-158.

5. Bulun SE (2009): Endometriosis. N Engl J Med 360: 268-279.

6. Kubatova A, Erdem A, Erdem M, et al. (2013): Serum cytokine and growth factor levels in patients with endometriosis. Centr Eur J Immunol 38: 500-504.

7. Carmona F, Chapron C, Martínez-Zamora MA, et al. (2012): Ovarian endometrioma but not deep infiltrating endometriosis 
is associated with increased serum levels of interleukin-8 and interleukin-6. J Reprod Immunol 95: 80-86.

8. Moini A, Malekzadeh F, Amirchaghmaghi E, et al. (2013): Risk factors associated with endometriosis among infertile Iranian women. Arch Med Sci 9: 506-514.

9. Agic A, Xu H, Finas D, et al. (2006): Is endometriosis associated with systemic subclinical inflammation? Gynecol Obstet Invest 62: 139-147.

10. Kılıc SH, Evsen S, Tasdemir N, et al. (2007): Follicular fluid vascular endothelial growth factor and tumour necrosis factor a concentration in patients with endometriosis undergoing ICSI. Reprod Biomed Online 15: 316-320.

11. Zulfikaroglu E, Kılıc S, Islimye M, et al. (2011): Efficacy of anti-tumor necrosis factor therapy on endometriosis in an experimental rat model. Arch Gynecol Obstet 283: 799-804.

12. Bedaiwy MA, Falcone T, Sharma RK, et al. (2002): Prediction of endometriosis with serum and peritoneal fluid markers: a prospective controlled trial. Hum Reprod 17: 426-431.

13. Revised American Society for Reproductive Medicine classification of endometriosis: 1996 (1997): Fertil Steril 67: 817-821.

14. Wu MY, Ho HN (2003): The role of cytokines in endometriosis. Am J Reprod Immunol 49: 285-296.

15. OuYang Z, Hirota Y, Osuga Y, et al. (2008): Interleukin-4 stimulates proliferation of endometriotic stromal cells. Am J Pathol 173: 463-469.

16. Berkkanoglu M, Arici A (2003): Immunology and endometriosis. Am J Reprod Immunol 50: 48-59.

17. Dmowski WP, Braun DP (2004): Immunology of endometriosis. Best Pract Res Clin Obstet Gynaecol 18: 245-263.

18. Bedaiwy MA, Falcone T (2004): Laboratory testing for endometriosis. Clin Chim Acta 340: 41-56.

19. Ohata Y, Harada T, Miyakoda H, et al. (2008): Serum interleukin-8 levels are elevated in patients with ovarian endometrioma. Fertil Steril 90: 994-999.

20. Martínez S, Garrido N, Coperias JL, et al. (2007): Serum interleukin-6 levels are elevated in women with minimal-mild endometriosis. Hum Reprod 22: 836-842.

21. Mier-Cabrera J, Jiménez-Zamudio L, García-Latorre E, et al. (2011): Quantitative and qualitative peritoneal immune profiles, T-cell apoptosis and oxidative stress-associated characteristics in women with minimal and mild endometriosis. BJOG 118: 6-16.

22. Khan KN, Masuzaki H, Fujishita A, et al. (2004): Higher activity by opaque endometriotic lesions than nonopaque lesions. Acta Obstet Gynecol Scand 83: 375-382.

23. Velasco I, Acién P, Campos A, et al. (2010): Interleukin-6 and other soluble factors in peritoneal fluid and endometriomas and their relation to pain and aromatase expression. J Reprod Immunol 84: 199-205.

24. Somigliana E, Vigano P, Tirelli AS, et al. (2004): Use of the concomitant serum dosage of CA 125, CA 19-9 and interleukin-6 to detect the presence of endometriosis. Results from a series of reproductive age women undergoing laparoscopic surgery for benign gynaecological conditions. Hum Reprod 19: 1871-1876.

25. Milewski Ł, Barcz E, Dziunycz P, et al. (2008): Association of leptin with inflammatory cytokines and lymphocyte subpopulations in peritoneal fluid of patients with endometriosis. J Reprod Immunol 79: 111-117.

26. Milewski Ł, Dziunycz P, Barcz E, et al. (2001): Increased levels of human neutrophil peptides 1,2, and 3 in peritoneal fluid of patients with endometriosis: association with neutrophils, T cells and IL-8. J Reprod Immunol 91: 64-70.

27. Lu D, Song H, Shi G (2013): Anti-TNF- $\alpha$ treatment for pelvic pain associated with endometriosis. Cochrane Database Syst Rev 3:CD008088.

28. Cho SH, Oh YJ, Nam A, et al. (2007): Evaluation of serum and urinary angiogenic factors in patients with endometriosis. Am J Reprod Immunol 58: 497-504.

29. Lee GH, Choi YM, Kim SH, et al. (2008): Association of tumor necrosis factor-a gene polymorphisms with advanced stage endometriosis. Human Reproduction 23: 977-981.

30. Teramoto M, Kitawaki J, Koshiba H, et al. (2004): Genetic contribution of tumor necrosis factor (TNF)-alpha gene promoter $(-1031,-863$ and -857$)$ and TNF receptor 2 gene polymorphisms in endometriosis susceptibility. Am J Reprod Immunol 51: 352-357.

31. Rogus J, Beck JD, Offenbacher S, et al. (2008): IL1B gene promoter haplotype pairs predict clinical levels of interleukin-1beta and C-reactive protein. Hum Genet 123: 387-398.

32. Singh H, Sachan R, Goel H, Mittal B (2008): Genetic variants of interleukin-1RN and interleukin-1b genes and risk of cervical cancer. BJOG 115: 633-638.

33. Wunder DM, Mueller MD, Birkhauser MH, Bersinger NA (2006): Increased ENA-78 in the follicular fluid of patients with endometriosis. Acta Obstet Gynecol Scand 85: 336-342.

34. Gupta S, Goldberg JM, Aziz N, et al. (2008): Pathogenic mechanisms in endometriosis-associated infertility. Fertil Steril 90: 247-257.

35. Lambert S, Santulli P, Chouzenoux S, et al. (2014): Endometriosis: Increasing concentrations of serum interleukin- $1 \beta$ and interleukin-1sRII is associated with the deep form of this pathology. J Gynecol Obstet Biol Reprod (Paris) 43: 735-743.

36. Kalu E, Sumar N, Giannopoulos T, et al. (2007): Cytokine profiles in serum and peritoneal fluid from infertile women with and without endometriosis. J Obstet Gynaecol Res 33: 490-495.

37. Wickiewicz D, Chrobak A, Gmyrek GB, et al. (2013): Diagnostic accuracy of interleukin-6 levels in peritoneal fluid for detection of endometriosis. Arch Gynecol Obstet 288: 805-814.

38. Drosdzol-Cop A, Skrzypulec-Plinta V (2012): Selected cytokines and glycodelin A levels in serum and peritoneal fluid in girls with endometriosis. J Obstet Gynaecol Res 38: 12451253.

39. Clayton DG, Walker NM, Smyth DJ, et al. (2005): Population structure, differential bias and genomic control in a large-scale, case-control association study. Nat Genet 37: 1243-1246.

40. Elshal MF, McCoy JP (2006): Multiplex bead array assays: performance evaluation and comparison of sensitivity to ELISA. Methods 38: 317-323. 